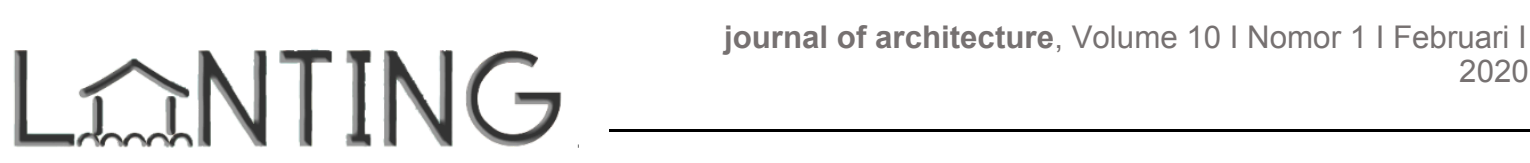

\title{
PUSAT PELATIHAN ATLET FUTSAL KABUPATEN HULU SUNGAI TENGAH
}

\author{
Muhtasar Tajri \\ Program Studi Teknik Arsitektur Fakultas Teknik Universitas Lambung Mangkurat \\ H1b115050@mhs.ulm.ac.id \\ Nurfansyah \\ Program Studi Teknik Arsitektur Fakultas Teknik Universitas Lambung Mangkurat \\ nfsarsitek@gmail.com
}

\begin{abstract}
ABSTRAK
Olahraga futsal merupakan olahraga yang paling populer di daerah Hulu Sungai Tengah, olahraga futsal sangat disukai oleh masyarakat di daerah tersebut, Meskipun olahraga bola futsal sangat populer di kabupaten Hulu Sungai Tengah, dalam penyediaan sarana dan prasarana untuk olahraga Futsal bisa dibilang kurang memadai. Pusat Pelatihan Atlet Futsal Kabupaten Hulu Sungai Tengah adalah sebuah kawasan yang akan menjadi tempat para atlet untuk meningkatkan kualitas diri ataupun tim, tempat yang merupakan sistem pendukung perkembangan para atlet untuk meningkatkan kualitasnya . untuk menunjang hal tersebut dilakukan pendekatan. Pada perancangan Pusat Pelatihan Atlet Futsal Kabupaten Hulu Sungai Tengah, dengan pendekatan Green Building , kualitas diri dari para pengguna bangunan dapat meningkat sehingga meningkatkan Green Building kinerja pelatihan para atlet, dan para atlet pun dapat meningkatkan kualitasnya, baik dari segi teknik, fisik, maupun mental para atlet di dalam Pelatihan Atlet Futsal Kabupaten Hulu Sungai Tengah.
\end{abstract}

Kata kunci: Pusat Pelatihan, Futsal, Sistem Pendukung Perkembangan, Green Building..

\section{ABSTRACT}

Futsal is the most popular sport in Hulu Sungai Tengah district, futsal its very loved sport in that region, although futsal is the most popular sport in Hulu Sungai Tengah District, in the provide of futsal facilities is inadequate. Hulu Sungai Tengah District Futsal Training Center is the area that will be the place of region futsal player to improve the quality of themselves or the team, a place that will be support development system for the region futsal player to improve their quality, to support that's will be approach the Green Building concept on the design of Hulu Sungai Tengah District Futsal Training Center. With the Green Building approach, quality of the building users can improve so that the training performance of region futsal players increases. And the region futsal player can improve their quality, both in terms of physical, technical, and mental of region futsal players in the Hulu Sungai Tengah District Futsal Training Center.

Keywords: Training Center, Futsal, Support Development System, Green Building. 


\section{PENDAHULUAN}

Olahraga futsal merupakan olahraga yang paling populer di daerah Hulu Sungai Tengah, olahraga futsal sangat disukai oleh masyarakat di daerah tersebut. Banyak perlombaan olahraga futsal yang rutin diadakan di daerah Hulu Sungai Tengah baik dalam skala kecil (RT,RW, desa) maupun skala besar (kecamatan, kabupaten). Karena tingginya tingkat kompetisi tersebut, banyak terdapat atlet-atlet bola futsal yang berkualitas di kabupaten Hulu Sungai Tengah, sekarang ini olahraga bola futsal kabupaten Hulu Sungai Tengah dapat dikatakan sangat berprestasi. Karena sering mewakili, bahkan menjuarai suatu kompetisi olahraga futsal baik itu skala nasional maupun internasional.

Meskipun olahraga bola futsal sangat populer di Kabupaten Hulu Sungai Tengah, dalam penyediaan sarana dan prasarana untuk olahraga Futsal di daerah kabupaten Hulu Sungai Tengah bisa dibilang kurang memadai, karena para atlet tersebut berlatih di lapangan umum maupun lapangan warga setempat. Untuk latihan fisik seperti pergi ke gym para atlet tersebut harus mengeluarkan dana sendiri untuk latihan di gym umum. Di daerah kabupaten Hulu Sungai Tengah hanya terdapat 4 lapangan futsal yang tersedia, yaitu ;

Tabel 1. Data Lapangan Futsal Di Kabupaten Hulu Sungai Tengah

\begin{tabular}{|c|c|c|c|c|c|c|}
\hline \multirow[t]{2}{*}{$\begin{array}{l}\text { Lok } \\
\text { asi }\end{array}$} & Nama & $\begin{array}{l}\text { Juml } \\
\text { ah }\end{array}$ & Jenis & $\begin{array}{c}\text { Lapan } \\
\text { gan }\end{array}$ & Waktu & $\begin{array}{l}\text { penye } \\
\text { waan }\end{array}$ \\
\hline & $\begin{array}{l}\text { Lapa } \\
\text { ngan }\end{array}$ & $\begin{array}{l}\text { Lapa } \\
\text { ngan }\end{array}$ & $\begin{array}{l}\text { Rump } \\
\text { ut } \\
\text { sinteti } \\
\text { s }\end{array}$ & Matras & $\begin{array}{l}\text { Week } \\
\text { day }\end{array}$ & $\begin{array}{c}\text { weeke } \\
\text { nd }\end{array}$ \\
\hline $\begin{array}{l}\text { Kota } \\
\text { Bar } \\
\text { abai }\end{array}$ & $\begin{array}{l}\text { Juwi } \\
\text { ta } \\
\text { futsa } \\
\text { I }\end{array}$ & 1 & - & 1 & $\begin{array}{l}\text { Jam } \\
16.00- \\
23.00\end{array}$ & $\begin{array}{l}\text { Jam } \\
08.00- \\
23.00\end{array}$ \\
\hline $\begin{array}{c}\mathrm{Ga} \\
\mathrm{mba} \\
\mathrm{h}\end{array}$ & $\begin{array}{l}\text { Gam } \\
\text { bah } \\
\text { futsa } \\
\text { I }\end{array}$ & 2 & 1 & 1 & $\begin{array}{l}\text { Jam } \\
16.00- \\
23.00\end{array}$ & $\begin{array}{l}\text { Jam } \\
08.00- \\
23.00\end{array}$ \\
\hline
\end{tabular}

\begin{tabular}{|c|c|c|c|c|l|l|}
\hline $\begin{array}{c}\text { Paju } \\
\text { kun } \\
\text { gan }\end{array}$ & - & 2 & 1 & 1 & $\begin{array}{l}\text { Jam } \\
16.00-\end{array}$ & $\begin{array}{l}\text { Jam } \\
08.00- \\
23.00\end{array}$ \\
\hline $\begin{array}{c}\text { Hau } \\
r \\
\text { gadi } \\
\text { ng }\end{array}$ & - & 1 & - & 1 & $\begin{array}{l}\text { Jam } \\
16.00-\end{array}$ & $\begin{array}{l}\text { Jam } \\
08.00- \\
23.00\end{array}$ \\
\hline
\end{tabular}

Sumber;penulis,2020.

Dari ke 4 lapangan tersebut, hanya 2 lapangan yang dipakai untuk latihan yaitu lapangan futsal juwita dan gambah, lapangan futsal juwita dan gambah sering dipakai untuk latihan karena lebih lengkap dari segi fasilitas dan mudah dicapai dari pusat kota.

\section{PERMASALAHAN}

Bagaimana rancangan sebuah pusat pelatihan futsal yang dapat menunjang kebutuhan atlet bola futsal dan dapat menjadi sistem pendukung perkembangan fisik, teknik dan psikologis para atlet bola futsal Kabupaten Hulu Sungai Tengah.

\section{TINJAUAN PUSTAKA}

\section{A. Pengertian Judul}

Pusat berarti pokok pangkal atau yang menjadi pumpunan berbagai macam urusan,hal, dan sebagainya, Pusat berarti sesuatu yang membawahkan berbagai bagian, sesuatu yang menjadi pumpunan dari bagian-bagian.

Menurut Bernardin dan Russell (1998:172) training is defined as any attempt to improve employee performance on a current held job or one related to it. This usually means changes in spesific knowledges, skills, attitudes, or behaviors. To be effective, training should involve a learning experience, be a planned organizational activity, and bedesigned in response to identified needs. Jadi pelatihan didefinisikan sebagai berbagai usaha pengenalan untuk mengembangkan kinerja tenaga kerja pada pekerjaan yang dipikulnya atau juga sesuatu berkaitan 
dengan pekerjaannya. Hal ini biasanya berarti melakukan perubahan perilaku, sikap, keahlian, dan pengetahuan yang khusus atau spesifik, agar pelatihan menjadi efektif maka di dalam pelatihan tersebut diharuskan meliputi suatu pembelajaran dari pengalaman-pengalaman sebelumnya, pelatihan diharuskan menjadi kegiatan keorganisasian yang terencana serta dirancang di dalam menanggapi kebutuhan yang teridentifikasi.

\section{Berdasarkan Never Ending} Transfusing-Application Training (NET-at), Pelatihan merupakan suatu kegiatan belajar ataupun praktik untuk sesuatu tujuan baik, dilakukan dengan cara berulang-ulang serta terus-menerus agar dapat meningkatkan kemampuan (continuously and never end) manusia, serta fitrahnya.

Jadi pusat pelatihan berarti tempat dimana para atlet berkumpul untuk meningkatkan kualitas diri dan skill mereka dengan cara melakukan pembelajaran danpraktik yang dilakukan secara berulang-ulang.

Futsal merupakan jenis permainan bola yang permainannya dimainkan dengan 2 tim, dimana masing-masing tim terdiri dari 5 orang disetiap tim. Tujuan dari permainan ini yaitu setiap tim berlomba untuk memasukkan bola ke gawang lawan, dengan cara memanipulasi bola dengan menggunakan kaki. Selain lima pemain utama, setiap regu juga diizinkan memiliki pemain cadangan. Tidak seperti permainan sepak bola dalam ruangan Lainnya, lapangan futsal dibatasi garis, bukan net atau papan.

Futsal juga sering dikenal dengan berbagai nama lain. Istilah "futsal" yang sering kita dengar merupakan istilah internasionalnya, futsal berasal dari kata Spanyol atau Portugis, yaitu futbol (sepak bola) dan sala (dalam ruangan).

\section{B. Tinjauan Gedung Olahraga}

Gedung olahraga merupakan tempat untuk melakukan berbagai macam jenis kegiatan olahraga lebih, baik latihan ataupun pertandingan di dalam lapangan dengan ruang tertutup. (Departemen Pekerjaan Umum,1994) Gedung olahraga terdiri dari tipe $A, B$ dan $C$. Klasifikasi ini menyangkut penggunaan, ukuran minimal matra (dimensi) ruang serta kapasitas penonton, seperti diuraikan dalam Tabel yang ditentukan Departemen Pekerjaan

Umum,1994:

Tabel 2. Klasifikasi Gedung Olahraga

\begin{tabular}{|c|c|}
\hline $\begin{array}{c}\text { Klasifikasi Gedung } \\
\text { Olahraga }\end{array}$ & $\begin{array}{c}\text { Jumlah Penonton } \\
\text { (Jiwa) }\end{array}$ \\
\hline Tipe A & $3000-5000$ \\
\hline Tipe B & $1000-3000$ \\
\hline Tipe C & Maksimal 1000 \\
\hline
\end{tabular}

Sumber; Standar Nasional Indonesia (SNI)

Penguraian masing-masing klasifikasi gedung olahraga sebagai berikut berdasarkan lingkup wilayah penggunaannya:

- Gedung olahraga tipe A adalah gedung olahraga dimana didalam penggunaan layanannya mencakup wilayah Propinsi/ Daerah Tingkat I

- Gedung olahraga tipe B adalah gedung olahraga dimana didalamnya penggunaan layanan mencakup wilayah Kabupaten/ Kotamadya.

- Gedung olahraga tipe C adalah gedung olahraga dimana di dalam penggunaan layanannya meliputi wilayah Kecamatan.

\section{Tinjauan Gedung Futsal}

Setiap olahraga mempunyai sarana dan prasarana masing-masing di dalam pengaplikasiannya, begitu juga dengan futsal. Dalam permainan futsal peraturan-peraturan resmi yang telah ditetapkan oleh Federation International de 
Football Association (FIFA), yang merupakan suatu badan yang mengatur seluruh peraturan tentang olahraga sepakbola ataupun futsal. Berikut adalah peraturan-peraturan dalam olahraga futsal tentang standar sarana dan prasarana yang diperlukan dalam permainan futsal.

\section{Lapangan Futsal}

Fasilitas yang paling utama di dalam olahraga futsal yaitu lapangan futsal yang memiliki bentuk persegi panjang, dimana garis samping (touchline) harus lebih panjang dari garis gawang (goal line). Lapangan olahraga futsal memiliki bentuk persegi panjang dengan ukuran panjang 25-42 meter dan lebar 15-25 meter. Untuk pertandingan internasional menggunakan ukuran panjang 38-42 meter dan lebar 18-25 meter. (Murhananto, Dasar-Dasar Permainan Futsal)

Seperti halnya lapangan sepakbola, lapangan olahraga futsal juga ditandai dengan adanya garis. Garis-garis ini termasuk didalam daerah permainan yang dibatasinya. Dua garis batas yang panjang disebut dengan garis samping dan dua garis pendek disebut dengan garis gawang. Lebar garis pembatas ini $8 \mathrm{~cm}$.

Lapangan permainan futsal dibagi dalam dua bagian oleh sebuah garis tengah, dimana dalam garis terdapat titik tengah yang dikelilingi oleh lingkaran yang berdiameter 6 meter. Dalam lapangan terdapat daerah pinalti berbentuk busur dengan jari-jari 6 meter. Titik pinalti terdapat dua jenis, yang pertama memiliki jarak 6 meter dari titik tengah garis gawang sedangkan untuk yang kedua berjarak 10 meter dari titik tengah garis gawang. Pada setiap sudut lapangan terdapat daerah tendangan sudut berupa $1 / 4$ lingkaran yang memiliki jari-jari $25 \mathrm{~cm}$.

\section{Tribun Penonton}

Syarat-syarat Tribun penonton yaitu harus memenuhi syarat dasar agar dapat mewujudkan tribun yang baik untuk penonton, antara lain meliputi:
Luas area tribun harus mencukupi untuk menampung jumlah penonton yang diinginkan.

Penonton diusahakan sedekat mungkin dari lapangan dan jarak pandang penonton dengan lapangan diusahakan optimal tanpa mengurangi faktor keamanan serta kenyamanan penonton ataupun atlit yang sedang bertanding.

- $\quad$ Penonton diusahakan diletakkan pada tempat yang memiliki sudut pandang optimal dan berhubungan langsung dengan lapangan permainan.

- Keamanan dan kenyamanan terjamin untuk semua pengguna tribun.

\section{Jenis Lapangan Futsal}

FIFA telah menetapkan bahwa permukaan lapangan futsal wajib rata, tidak kasar,atau mulus. Permukaan lapangan futsal standar terbuat dari bahan kayu atau lantai parket, atau bahan lainnya. Hindari penggunaan beton atau konblok pada permukaan lapangan futsal. Keselamatan pemain harus menjadi poin utama saat memilih bahan untuk pembuatan lapangan futsal.

Sekarang ini telah banyak dibangun tempat bermain futsal dengan menggunakan berbagai jenis lapangan. Terdapat 3 jenis lapangan futsal yang paling sering ditemui,antara lain:

$$
\text { 1. Lapangan Futsal Lantai }
$$

Bahan Vinyl banyak dipilih untuk membuat lapangan futsal. Bahan ini terdiri dari lapisan karet atau rubber sebagai material utama pembuatan lapangan futsal. Jenis lapangan yang satu ini banyak disukai oleh para pemain karena memberikan kestabilan aliran bola karena permukaannya yang rata. Selain itu, tekstur lapangan yang empukdapat mengurangi rasa sakit saat pemain terjatuh. Kekurangan dari lapangan futsal jenisvinyl ini terletak dari segi ketahanan bahan. Vinyl sangat mudah terkelupas saat digunakan dalam jangka waktu yang lama. 


\section{Lapangan Futsal Rumput Sintetis}

Jenis lapangan futsal yang satu ini sangat populer digunakan di Indonesia karena disukai oleh para pemain. Banyak tempat bermain futsal yang memakai rumput sintetis

sebagai bahan material permukaan lapangan. Penggunaan rumput sintetis memudahkan pemain saat mengontrol bola. Selain itu, rumput sintetis juga dianggap aman saat pemain terjatuh. Namun, kekurangan dari bahan rumput sintetis adalah kadang menimbulkan luka saat terseret atau tergesek karena rumput sintetis memiliki ujung yang agak tajam. Lapangan futsal rumput sintetis bukanlah jenis lapangan standar FIFA sehingga tidak pernah digunakan dalam pertandingan resmi. Lapangan ini hanya digunakan untuk tujuan hiburan atau permainan biasa saja.

\section{Lapangan Futsal Semen}

Pemilihan semen sebagai lantai lapangan futsal sering ditujukan pada lapangan futsal yang terletak di luar ruangan atau outdoor. Bahan semen dianggap lebih tanah dari perubahan cuaca, seperti terik matahari dan hujan. Selain itu, permukaan lapangan futsal dengan bahan semen memiliki kerataan yang cukup baik, serta biaya pembuatan yang murah. Banyak pengusaha sewa lapangan futsal outdoor yang menggunakan bahan ini.

\section{Lapangan Futsal Parquette}

Penggunaan bahan Parquet untuk membuat lapangan futsal banyak digunakan di Amerika Latin dan Eropa. Di Indonesia sendiri, jenis lapangan ini kurang begitu populer. Penggunaan bahan ini banyak ditemui pada lapangan futsal indoor dalam GOR. Lapangan futsal Parquette memiliki tingkat kekesatan yang tinggi, sehingga mengurangi resiko pemain terpeleset saat bermain futsal. Permukaannya yang halus dan rata membuat aliran dan laju bola yang stabil.

\section{Lapangan Futsal Taraflex Polyethylene}

Lapangan futsal taraflex hampir sama dengan lapangan jenis parquet, bedanya adalah lapangan ini berasal dari bahan polyethylene atau biji plastik yang telah dipadatkan. Jenis lapangan yang satu ini populer digunakan di eropa sebagai alternatif bahan parquet.

\section{Lapangan Futsal Karpet Plastik}

Jenis lapangan futsal yang terakhir adalah lapangan futsal yang permukaannya terbuat dari material plastik. Bahan ini sangat mirip dengan bahan pembuatan taraflex yang menggunakan polyethylene. Perbedaannya adalah bahan karpet plastik ini terdiri dari banyak lembaran-lembaran yang mudah dibongkar pasang sehingga mudah untuk dipindahkan. Penggunaan bahan plastik sebagai lapangan futsal banyak dipilih karena memiliki nilai ekonomis yang tinggi dan tahan lama.

\section{PEMBAHASAN}

A. Lokasi

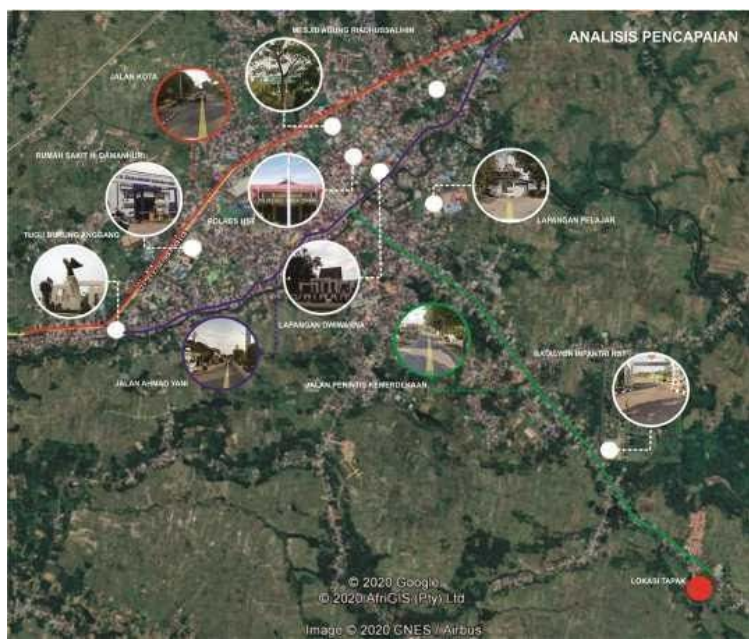

Gambar 1. Lokasi Tapak

Sumber; Penulis, Diolah dari Google Earth, 2019.

Lokasi site berada di jalan perintis kemerdekaan, desa Gambah, kecamatan Barabai, kabupaten Hulu Sungai Tengah, Kalimantan Selatan, Indonesia. Site memiliki bentuk persegi panjang dengan Luas $150 \mathrm{~m}$ 
x 400m (6 ha), berada di area persawahan dan hutan dengan kontur tanah yang datar, site memiliki batasan sebagai berikut :

- Batas sisi depan site: Jln. perintis kemerdekaan

- Batas sisi kiri site: Sawah dan hutan

- Batas sisi belakang site: Sawah dan hutan

- Batas sisi kanan site: Sawah Dan hutan

Terdapat beberapa aturan yang harus dipenuhi dalam melaksanakan pembangunan di suatu daerah, berikut peraturan pembangunan yang ada di daerah Gambah, kecamatan Barabai yang harus dipenuhi :

- Garis Sempadan Bangunan: 8M (untuk jalan desa yang berada di kecamatan)

- Koefisien Dasar Bagunan: max $60 \%$

- Koefisien Daerah Hijau: min 30\%

Lokasi dipilih atas pertimbangan yang mendukung pengadaan pusat pelatihan atlet futsal kabupaten Hulu Sungai Tengah, dengan pertimbangan sebagai berikut :

- Situasi daerah sekitar site tenang

- Kualitas udara di sekitar site sangat bagus

- Lokasi tapak berupa lahan yang masih kosong

- Dapat dicapai dengan mudah dari pusat kota

- Kondisi Jalan menuju site sangat bagus

\section{B. Konsep Rancangan}

\section{Konsep Ruang Luar}

Zoning kawasan diperlukan untuk mengelompokan zona bangunan agar tercipta harmonisasi yang pas antar bangunan, di dalam pusat pelatihan atlet futsal kabupaten Hulu Sungai Tengah ini, ada 4 zona kawasan yang akan dirancang, dimulai dari masuk zona kedatangan, lalu terus ke zona pencapaian yang ada di bagian tengah tapak, masuk zona transisi yang menghubungkan zona pencapaian dan zona pengembangan, lalu masuk zona pengembangan yang merupakan pusat dari aktivitas yang dilakukan di pusat pelatihan futsal kabupaten Hulu Sungai Tengah.
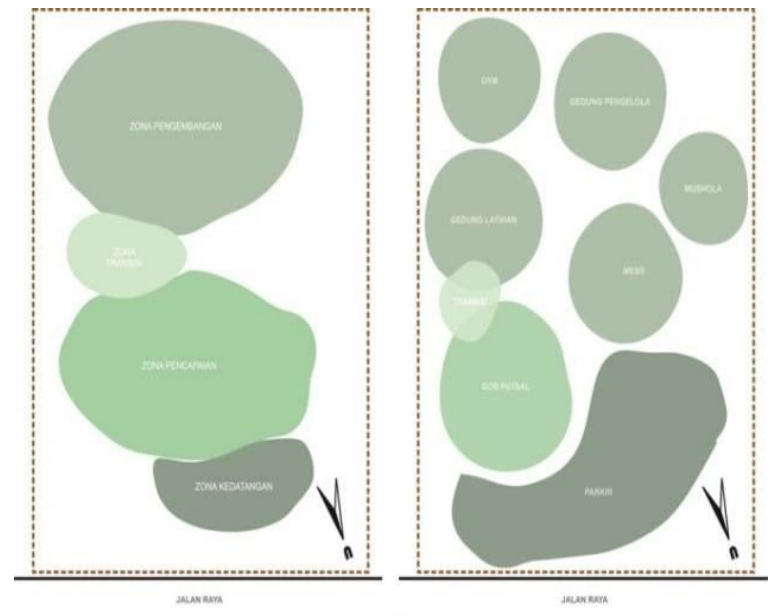

Gambar 2. Konsep Ruang Luar) Sumber; Penulis, 2019.

Pusat pelatihan atlet futsal kabupaten Hulu Sungai tengah ini terdapat 4 zona kawasan, pada zona-zona tersebut terdapat organisasi ruang yang terdapat didalamnya, yaitu :

- Zona kedatangan; Ruang parkir.

- Zona pencapaian; GOR futsal

- Zona transisi; Koridor

- Zona pengembangan; gedung latihan, gym, mess, gedung pengelola, musholla 
2. Konsep Sistem Perancangan

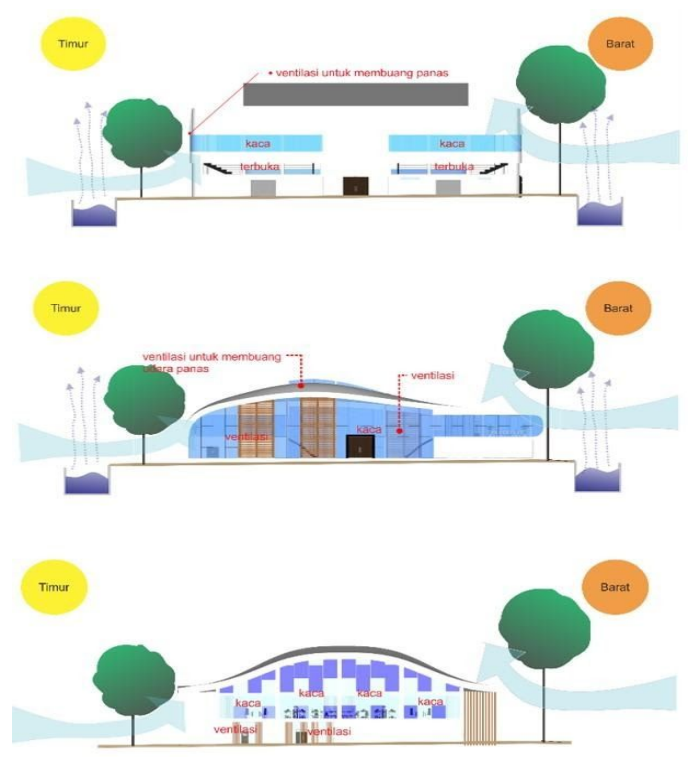

Gambar 3. konsep sistem rancangan Sumber; Penulis, 2020.

Untuk menciptakan kondisi lingkungan yang nyaman, ada beberapa pendekatan yang dilakukan

Bukaan cahaya yang luas diaplikasikan pada bagian utara dan selatan bangunan untuk memaksimalkan pencahayaan alami dari cahaya matahari.

Vegetasi diaplikasikan di sekitar bangunan berfungsi sebagai peneduh dan juga sebagai media untuk menangkap udara agar bisa maksimal masuk kedalam bangunan.

Croos ventilation diaplikasikan pada bangunan agar sirkulasi udara dalam ruangan ruangan dapat mengalir dengan lancar.

Pengaplikasian cooling effect disekitar bangunan ditujukan untuk menciptakan kenyamanan ruang luar dengan cara mengontrol kelembaban udara di ruang luar menggunakan kolam sebagai cooling effect.

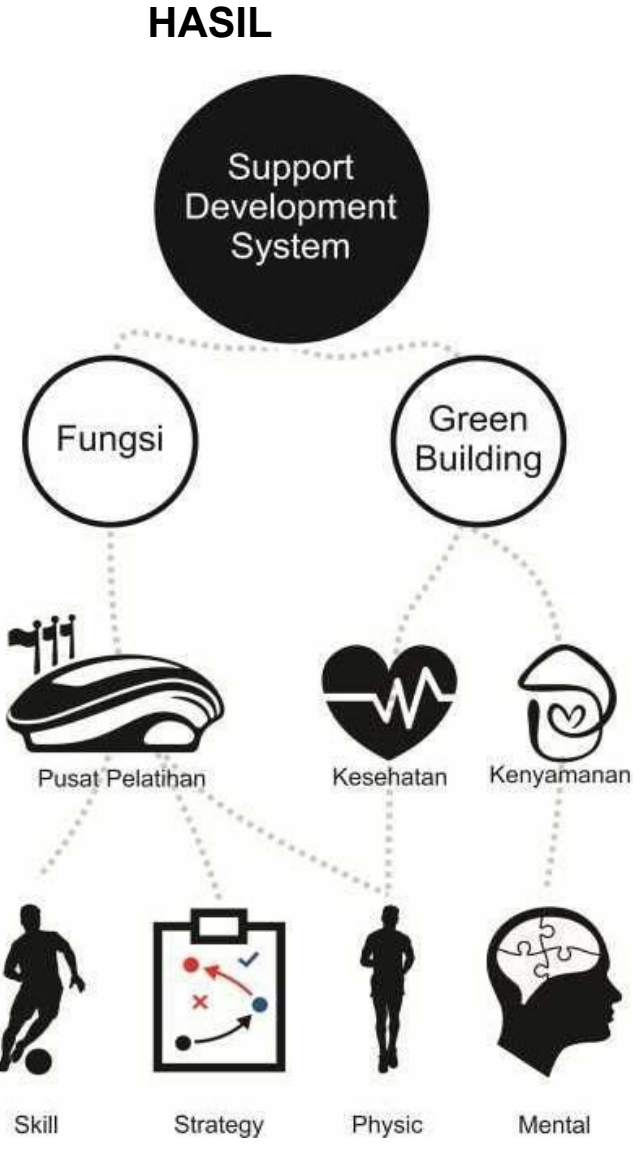

Gambar 4. Konsep Programatik Sumber; Penulis, 2020.

Konsep support development system adalah sebuah tatanan kawasan yang dapat menjadi penunjang perkembangan atlet futsal dan dapat menjadi tempat untuk menampung segala kegiatan para atlet futsal untuk berkembang, berlatih untuk meningkatkan kualitas diri maupun tim futsal kabupaten Hulu Sungai Tengah. 


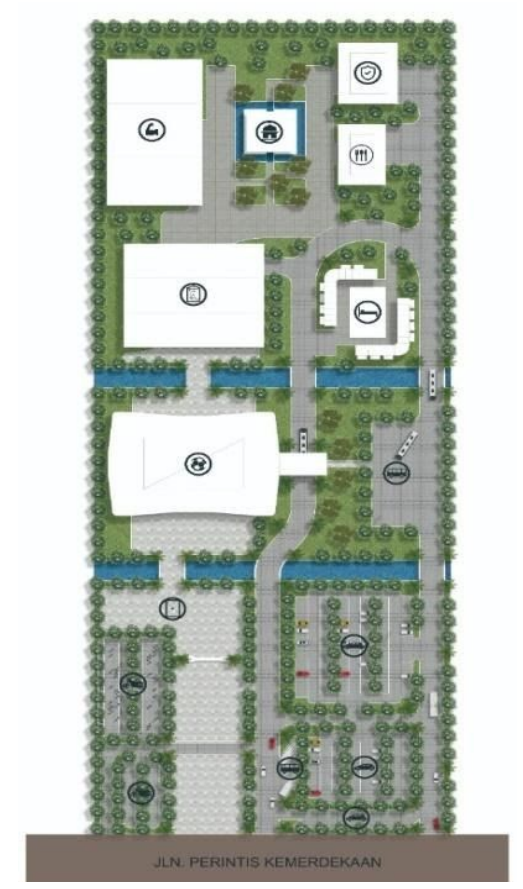

\begin{tabular}{|c|c|}
\hline LEGENDA & KETERANGAN \\
\hline GOT FUTSAL \\
GEDUNG LATIHAN \\
GEDUNG PENGEMBANGAN \\
MESS ATLET \\
KANTIN \\
GEDUNG PENGELOLA \\
MUSHOLLA \\
PALUN-ALUN \\
PARKIR MOBIL \\
PARKIR BUS BOR \\
\hline
\end{tabular}

Gambar 5. Site Plan pusat pelatihan futsal kabupaten hulu sungai tengah

Sumber; Penulis, 2020.

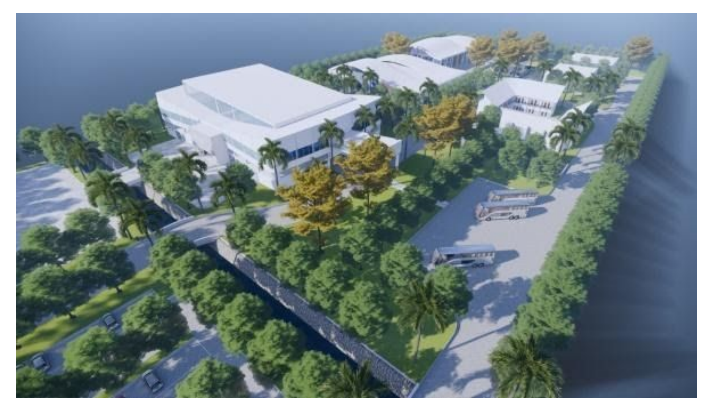

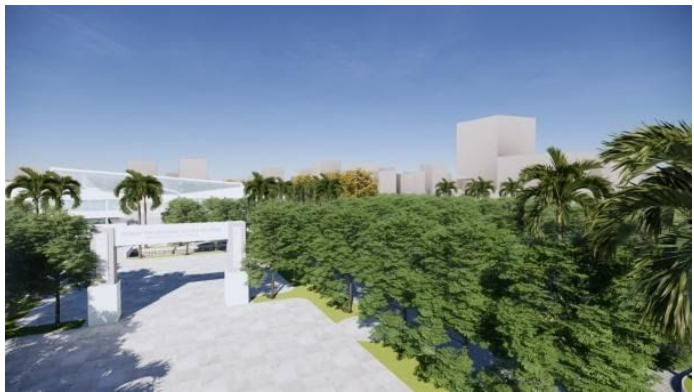

Gambar 6. Aerial View Kawasan Sumber; Penulis, 2020.
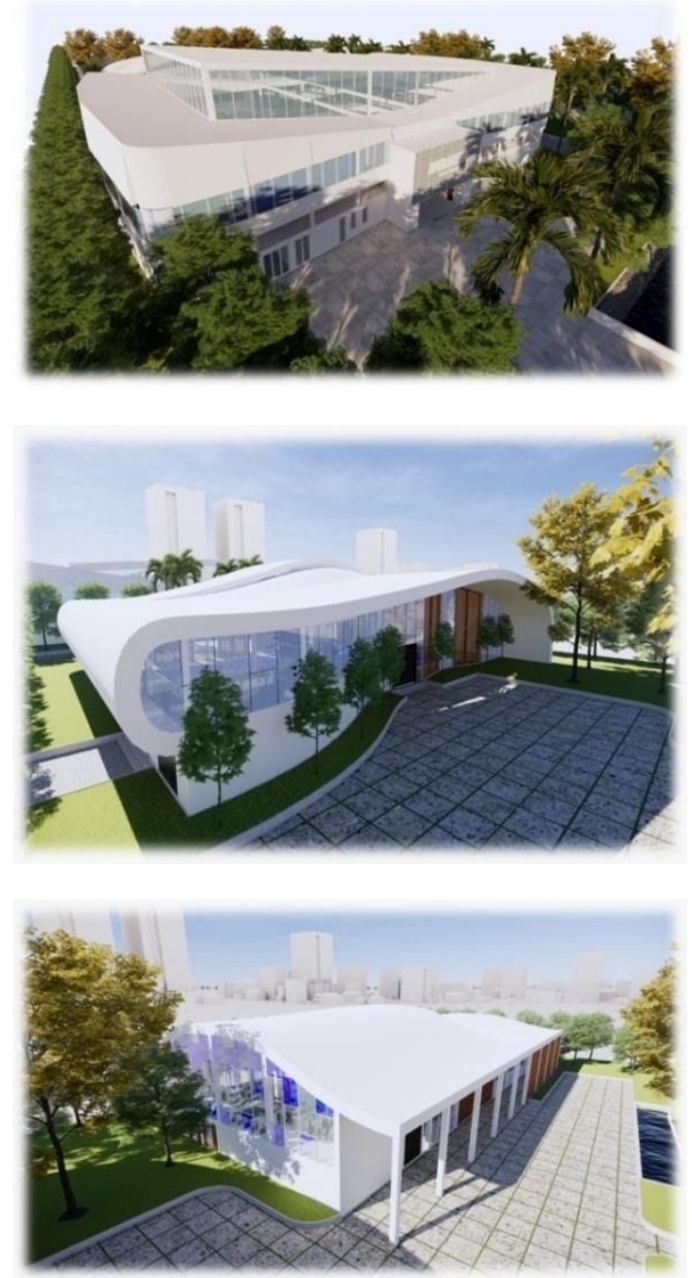

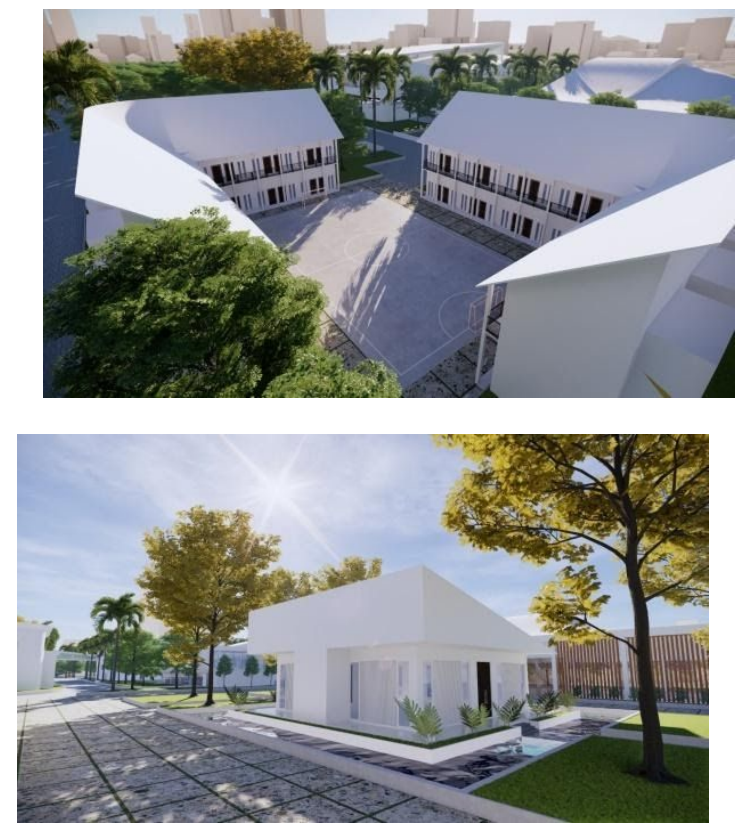

Gambar.6 Gambar desain bangunan Sumber; Penulis, 2020.

KESIMPULAN

Pusat pelatihan atlet futsal kabupaten hulu sungai tengah didesain dengan tujuan memberikan atlet futsal di kabupaten Hulu Sungai Tengah sebuah tempat untuk mewadahi segala kegiatan dan keperluan mereka untuk berlatih dan berkembang, hingga mampu meningkatkan kualitas mereka, dari segi fisik, skill, taktik, maupun mental mereka dalam bermain futsal, untuk itu diperlukan sebuah kawasan yang mampu untuk menampung segala kegiatan para atlet futsal dalam prosesnya untuk berkembang untuk menjadi seorang atlet futsal yang berprestasi.

Pusat pelatihan atlet futsal kabupaten Hulu Sungai Tengah di desain dengan konsep 'Support Development System", yaitu sebuah kawasan yang menjadi sistem pendukung perkembangan para atlet futsal kabupaten Hulu Sungai Tengah untuk meningkatkan kualitasnya, dengan beberapa komponen sistem yang ada di dalam kawasan pusat pelatihan. Yang dibungkus dengan penerapan konsep Green Building pada bangunan kawasan, yang sangat bermanfaat bagi kesehatan fisik dan mental para atlet dalam proses perkembangannya.

\section{DAFTAR PUSTAKA}

\section{Referensi Buku dan Jurnal}

FIFA Football Stadiums Technical recommendations and requirements

\section{Website}

IImusiana.com (Juni 2019) ukuran lapangan futsal standar fifa, diambil dari https://www.ilmusiana.com/2019/06/uk uran-lapangan-futsal-standar-fifa.html

Wikipedia (24 juli 2019). futsal dipetik 7 agustus 2019 diambil dari https://id.wikipedia.org/wiki/Futsal

Wikipedia (4 juli 2019). pelatihan dipetik 7 agustus 2019 diambil dari https://id.wikipedia.org/wiki/Pelatihan 